\title{
Los nuevos amos del mundo: la globalización de los medios de comunicación de masas
}

\author{
Julia R. CELA \\ Universidad Complutense de Madrid \\ jurodrig@ccinf.ucm.es
}

Recibido: 08/05/2012

Aceptado: 18/12/2012

\begin{abstract}
Resumen
Este artículo parte de un marco conceptual para definir sin equívocos el concepto de sociedad global de la información y sociedad civil global. Conceptos que nos sirven de introducción a la tesis que planteamos y explicamos: cómo los medios de comunicación se han constituido en el presente siglo en los nuevos amos del mundo, unidos claro está, al poder financiero del que forman parte, gracias a seis grandes corporaciones multimedia de carácter global.
\end{abstract}

Palabras clave: Globalización, Sociedad global de la información, Sociedad civil global, corporaciones multimedia, contrainformación.

\section{The New Owners of the World: the Globalitazion of Mass Media}

\begin{abstract}
This paper starts with a conceptual framework that defines unequivocally terms such as global Information Society and global Civil Society. These introductory terms lead us to the conclusion we sustain, and that we argument, that they are shaping mass media as the new owners of the world in the present century, obviously linked as they are to financial power through six big global multimedia corporations with monopoly features.
\end{abstract}

Keywords: Globalization, Global Information society, Global Civil society, multimedia corporations, counterinformation.

\section{Referencia normalizada}

CELA, Julia R. (2013): "Los nuevos amos del mundo: la globalización de los medios de comunicación de masas”. Estudios sobre el mensaje periodístico. Vol. 19, Núm. 1, págs.: 255-264. Madrid, Servicio de Publicaciones de la Universidad Complutense.

Sumario: 1. Introducción. 2. Metodología. 3. Del concepto de globalización al concepto de sociedad global de la información. 4. Los grandes grupos multimedia de comunicación. 5. La contrainformación: una alternativa al gran poder mediático. Internet una vía de escape y libertad. 6. Conclusiones. 7. Referencias bibliográficas

\section{Introducción}

Nunca como hoy, el mensaje periodístico había llegado a tantos receptores, nunca anteriormente había existido una difusión tan amplía de ese mensaje, gracias a los medios de comunicación de masas que lo hacen posible. Nunca como hoy, el emisor ha sido consciente de su gran poder de transmisión y eso es así, debido al gran canal que representan los medios de comunicación de carácter global, que llegan también a un receptor que se encuentra dentro de la sociedad global de la información.

Y es que hoy nos encontramos querámoslo o no en un proceso de globalización, que incluso para aquellos sociólogos más críticos se ha convertido en irreversible. El mundo global en el que nos encontramos comenzó a finales del siglo pasado con una globalización económica de los medios financieros transnacionales, y de ahí derivó rápidamente a la política, la cultura, el medio ambiente, etc., y por supuesto, a los me- 
dios de comunicación de masas totalmente relacionados no solo con los medios financieros, sino también, con el desarrollo de las tecnologías de información y comunicación, así como con la política, la cultura y el medio ambiente, a través de los mensajes que difunde.

Y la pregunta que debemos hacernos y que intentaremos contestar a lo largo de este artículo, es ver cómo afecta esa globalización a los medios de comunicación de masas, como en tan solo dos décadas, la globalización económica nos ha traído consigo también la globalización informativa, y con ella seis grandes grupos de comunicación que son hoy los dueños prácticamente de todo el mercado de la información en el mundo occidental, a quienes podríamos denominar: los nuevos amos del mundo. Estos nuevos amos son quienes hoy controlan los mensajes de carácter periodístico e informativo, y además sabemos que se encuentran íntimamente conectados a las redes financieras y tecnológicas, pero lo más importante es que estos nuevos amos configuran nuestra cultura, nuestra mentalidad, nuestro universo simbólico y la opinión pública mundial. Ante ese control a nivel global qué puede hacer el ciudadano indefenso, desde luego no mucho, pero sí debe contrastar como nunca la información, y sobre todo, en la medida que le sea posible constituirse como emisor e intentar hacer llegar a un receptor global su mensaje. La única alternativa que se le ofrece hasta el momento a ese gran poder mediático lo tiene gracias a Internet y las redes sociales, que podemos considerar una nueva vía de escape y libertad para esa sociedad civil global que también desea dejarse oír.

\section{Metodología}

En el presente artículo partimos de una conceptualización de sociedad global de la información y sociedad civil global, que pese a resultar hoy manida, por el contrario se está utilizando en muchos casos de forma equivocada, lo que nos lleva en el presente artículo a aclarar estos conceptos. Gracias a la exhaustiva investigación documentalconceptual hemos llegado a conclusiones que nos hacen posible demostrar en este trabajo que el concepto de globalización, es un concepto moderno del siglo XXI, aunque algunos quieran hacernos ver lo contrario. Una vez aclarado este marco conceptual previo que nos hace posible sumergirnos en la sociedad global de la información, para poder así contestar a la hipótesis principal que propone esta investigación: ¿quiénes son hoy los nuevos amos del mundo de la información? ¿quiénes son los dueños de los mensajes periodísticos que circulan en nuestra sociedad actual? Desde luego las grandes corporaciones financieras, pero ¿quiénes son dentro de ellas los portadores del mensaje periodístico? ¿quiénes controlan los grandes canales de información? Y como contraparte: ¿quiénes actúan de contrapoder, y a través de qué canales de comunicación? Todas estas preguntas y algunas más obtendrán respuesta en el análisis e investigación de este artículo.

\section{Del concepto de globalización al concepto de sociedad global de la información}

El siglo XXI es ya por excelencia el siglo de la sociedad de la información y del conocimiento, que ha venido dado gracias al gran auge que han alcanzado en toda la sociedad occidental el desarrollo de las TIC (Tecnologías de Información y Comunicación). Por ello nos encontramos sumergidos, -querámoslo o no- en una sociedad basada en 
una economía fundada en el conocimiento. El conocimiento, por lo tanto, se encuentra ahora ocupando el lugar central del crecimiento económico y de la elevación progresiva del bienestar social. Las inversiones en muchos países canalizadas a través de los proyectos $\mathrm{I}+\mathrm{D}+\mathrm{i}$ tienen como fin último, la producción y transmisión del conocimiento, un conocimiento que nos hace posible formatear el gran caudal de información que recibimos diariamente y que nos capacita para estructurarlo de forma que podamos interpretarlo y difundirlo en nuestra sociedad. (Cela, 2005: 147-148)

$\mathrm{Y}$ al igual que el concepto de sociedad de la información y del conocimiento ya se encuentra muy arraigado en este nuevo siglo, pasa lo mismo con el concepto de globalización, pues ya hace bastante tiempo que vivimos en una sociedad mundial de espacios abiertos en todos los órdenes, desde el económico, ecológico, político, cultural, etc; la tesis de una sociedad cerrada, de espacios cerrados es ficticia, pues ya no hay país, ni ningún grupo que en este siglo pueda vivir al margen de los demás. Como muy bien nos define Ulrich Beck, el concepto de globalización significa: "los procesos en virtud de los cuales los estados nacionales soberanos se entremezclan e imbrican mediante actores transnacionales y sus respectivas probabilidades de poder, orientaciones, identidades y entramados varios" (Beck, 2008: 33)

Cómo nos expresan los sociólogos aún aquellos más críticos con los procesos de globalización, estos se han hecho irreversibles, ya que la globalización económica de los medios financieros transnacionales, la cultural, política, ecológica o de los medios de comunicación se encuentra imbricada y relacionada entre sí de tal manera, que ya hace imparable este proceso en el que estamos todos sumidos. Ulrich Beck nos propone ocho razones que explican la irreversibilidad de la globalidad:

1. El ensanchamiento del campo geográfico y la creciente densidad del intercambio internacional, así como el carácter global de la red de mercados financieros y del poder cada vez mayor de las multinacionales. Hoy ese poder financiero internacional y las grandes multinacionales podemos considerarlo el primer poder, lo que llamaríamos los amos del mundo, y dentro de esas grandes y poderosas multinacionales se encuentran las de los medios de comunicación, íntimamente relacionadas con el poder financiero.

2. La revolución permanente en el terreno de la información y las tecnologías de la comunicación. El poder cada vez mayor y transnacional de las redes y las TIC.

3. La exigencia, universalmente aceptada, de respetar los derechos humanos, también considerada (de boquilla) como el principio de la democracia-. Esa exigencia que nos indica que si queremos pertenecer al club de primera, entonces debemos respetar los derechos humanos.

4. Las corrientes icónicas de las industrias globales de la cultura. Todo recibimos las mismas imágenes, la misma información a través de estas grandes multinacionales de la información, creadoras a su vez de la cultura y los referentes en los que nos formamos y configuramos nuestra propia información del mundo en el que habitamos, y desde luego también, nuestra propia opinión.

5. La política mundial postinternacional y policéntrica: junto a los gobiernos hay cada vez más actores transnacionales con cada vez mayor poder (multinacionales, organizaciones no gubernamentales, Naciones Unidas). El Estado tal como se configura en el siglo XIX ha ido perdiendo poder y en este siglo XXI 
se ha traspasado este poder a las grandes corporaciones financieras, multinacionales, organismos internacionales, $\mathrm{ONG}^{\prime}$ s, etc., que operan de forma no estatal y local sino de forma internacional y con carácter global.

6. El problema de la pobreza global. Uno de los grandes problemas que se plantea todavía en este siglo y que tiene una solución a nivel global.

7. El problema de los daños y atentados ecológicos globales. Otro de los grandes problemas de este siglo, que también solo tiene una solución de carácter global.

8. El problema de los conflictos transculturales en lugar concreto. El miedo en nuestras sociedades migratorias al otro, a la cultura enraizada que el otro posee y que es distinta a la nuestra. (Beck, 2008: 35-36)

Todo esto que hemos dicho, puede parecer que no es nada nuevo, pero sí que es nuevo en este siglo: es nueva la gran transnacionalidad que se está viviendo en nuestra vida cotidiana y sobre todo en el ámbito financiero, sin la intervención directa de los Estados nacionales; es nueva la transnacionalidad en los medios de comunicación (como luego veremos), también en el consumo y hasta en el turismo; nueva es la translocalización de la comunidad, el trabajo y el capital; nueva es la conciencia del peligro ecológico global; nueva es la percepción de los otros transculturales en nuestra propia vida; y nuevo es el nivel de circulación actual de las industrias culturales globales.

Cómo podemos comprobar la globalización ya está presente en nuestras vidas -y como muy bien observa el economista Joseph Stiglitz- abarca casi a todos los aspectos que nos rodean: al flujo internacional de ideas y conocimientos, al intercambio cultural, a la sociedad civil global y al movimiento global a favor del medio ambiente. Pero sobre todo, a la globalización económica, la cual implica a todos los países del mundo a través del flujo creciente de bienes y servicios, capital e incluso trabajo. Para Stiglitz la gran esperanza puesta en esta globalización es que sirviera para facilitar a los países pobres los mercados internacionales, que pudieran vender sus productos a precios más baratos, que pudieran trabajar y formarse en los países ricos y mandar a sus hogares remesas con las que ayudar a su familia y crear nuevas empresas. Pero la realidad es otra, la globalización dice Stiglitz no es mala en sí, el problema es como se ha gestionado "Ha sido la economía la que ha guiado a la globalización, sobre todo a través de la reducción de los costes de comunicación y transporte. Pero la política la ha conformado. Los países desarrollados -y en especial intereses particulares dentro de esos países- son los que han dictado en gran medida las reglas del juego, y por eso no hay que sorprenderse de que hayan conformado la globalización de acuerdo con sus propios intereses". (Stiglitz, 2006: 28)

$\mathrm{Y}$ ante esa realidad de una globalización que abarca todos los sectores de nuestra sociedad surge un nuevo concepto el de sociedad global de la información, que aúna la noción de era global y de era de la información, con el fin de impulsar el funcionamiento democrático de nuestras sociedades, gracias a una mayor participación de los ciudadanos en las tomas de decisiones, y a su vez, potenciar la capacidad de las naciones para cooperar entre sí. Pero como muy bien dice Mattelart, detrás de estos nobles principios de "cooperación entre los pueblos" que facilite la "conversación planetaria", se esconde una trampa, ya que para que este objetivo se lleve a cabo se hace necesario la apertura de los sistemas nacionales de telecomunicaciones, es decir, 
la privatización, siguiendo las líneas que impone el mercado de un capitalismo sin fricciones. (Mattelart, 2002: 65-80)

Esas privatizaciones en el sistema de telecomunicaciones de todos los países se llevó a cabo en la década de los años 90, facilitando así la creación de grandes corporaciones de telecomunicaciones que ayudaron también a la formación de las grandes empresas multinacionales de comunicación de masas.

\section{Los grandes grupos multimedia de comunicación}

Dentro de esta gran globalización económica en la que nos encontramos inmersos se haya también la globalización informativa. "Los grandes grupos multimedia -los nuevos amos del mundo- han entrado en una dinámica de alianzas, fusiones, absorciones y concentraciones, tratando de tomar posiciones en el dominio de una "infraestructura de la información global". (Reig, 2004: 64) Y no debemos olvidarnos de la importancia de los medios de comunicación en la formación de la opinión pública, y la opinión política de los ciudadanos, sobre todo de la televisión, que conforma la opinión de un 90 por ciento de la población, como muy bien dice Giovanni Sartori, la mayoría de la gente se informa a través de la televisión y opina según lo que ha visto en televisión, lo que no aparece en nuestras pantallas, no existe.

Ignacio Ramonet ha llegado a declarar que hoy en día, los mercados financieros son el primer poder, y que el segundo no sería el poder político, sino el de los medios de comunicación, que como vemos en este siglo han pasado del cuarto poder al segundo. E incluso habría que completar esta aseveración, ya que los mercados financieros colaboran de forma directa o indirecta en la actividad de los grupos de comunicación a los que pertenecen los medios de comunicación más influyentes, por lo que extraeríamos la lectura de que también dentro del primer poder se encuentra la comunicación y sus productos: los medios de los que emanan los mensajes.

Y puesto que los medios de comunicación son sobre todo, un negocio, las mismas tendencias generales que han transformado el mundo empresarial - globalización, digitalización, creación de redes y desregulación- también han alterado radicalmente las operaciones mediáticas. "Estas tendencias han eliminado prácticamente los límites de la expansión mediática permitiendo la consolidación del control oligopolístico de unas cuantas empresas sobre buena parte del núcleo de la red global de medios de comunicación. [...] Por lo tanto, la principal transformación organizativa de los medios de comunicación es la formación de redes globales de empresas multimedia interconectadas que se organizan en alianzas estratégicas." (Castells, 2009: 109-110)

¿Y entonces cuáles son esos grandes grupos multimedia que son hoy por hoy los amos del mundo de la comunicación?

Son seis grandes grupos que se encuentran ampliamente diversificados, es decir que van más allá del sector de las comunicaciones, pero son quienes configuran los mensajes de nuestro planeta y los que influyen directamente en la creación de nuestra realidad cultural.

- TIME WARNER-TBS-EMI-CNN (Estados Unidos e Inglaterra) Time Warner es propietaria de $\mathrm{CNN}$, (y del 50 por ciento de $\mathrm{CNN}+$ del grupo Prisa), colabora con Sony (Japón), y con Virgin que posee productos audiovisuales, tiendas, líneas aéreas, etc. También posee revistas principales como Time, Fortune, People, etc. Se 
encuentra apoyada por City Group. Y tiene convenios con Prisa, HBO, Cartoon Network, TNT, TCM, etc.

- VIACOM-CBS (Estados Unidos) a la que también pertenece los estudios de cine Paramount. Comparte con otras corporaciones canales de radio, de televisión y servicios de internet con AT\&T, Time-Warner, AOL, Reuters, News Corporation y Vivendi NBC. CBS anteriormente estuvo ligada a Westinghouse. En España se encuentra ligada al grupo Vocento.

- BERTELSMANN (Alemania) Fundada por la familia Mohn con origen editorial. También tiene la cadena audiovisual RTL, absorbió a Pearson (GB). Propietaria de la cadena audiovisual RTL, se encuentra ligada al mundo editorial en Estados Unidos. Gran penetración en el mundo discográfico a través de BMG (Bertelsmann Music Group). Presencia en España: a través del accionariado de Antena 3 TV, del Banco de Santander, El Corte Inglés, el Banco de Sabadell. Propietaria de editoriales como el Círculo de lectores, Plaza \& Janes, y Lumen, entre otras.

- ABC-DISNEY (Estados Unidos). Las cadenas televisivas de ABC News, agencias audiovisuales. Y el Disney Channel mundial, plataformas digitales (en España a través de Prisa y Telefónica), el mercado latinoamericano, y todo el negocio de merchandising gracias a sus acuerdos con McDonalds. Y también se encuentra en este grupo mediático General Electric.

- VIVENDI UNIVERSAL (Francia, Canadá y Estados Unidos). Nace con el canal de aguas francés. Está desarrollando una importante presencia en la Europa del Este. Posee los estudios Universal. Se desprendió de las editoriales francesas que pertenecían al grupo y que han pasado a Murdoch, Continúa con su división medioambiental a través de Vivendi Enviroment (tratamientos de aguas y reciclado), es accionista de la empresa española Construcciones y Contratas. También tiene presencia en España a través de Prisa.

- NEWS CORPORATION (Inglaterra, Estados Unidos y antes Australia) El grupo de Murdoch cuyo mayor poder es la televisión por satélite Star y FOX, también de los estudios Century Fox, accionista de un tercio de General Motors, de periódicos como Time de Londres y Financial Times que antes pertenecía a Bertelsmann. Presencia en España a través de Unedisa (El Mundo), grupo Z. Propietario de MySpace. Compró el grupo Dow Jones, que edita, entre otros, The Wall Street Journal. Tiene acciones en el grupo Rotana de capital saudí que le conecta con: Citigroup, Apple, Sacks, PepsiCo., además posee hoteles de lujo y participaciones en numerosas sociedades saudíes. (Reig, 2011:55-68)

Estas son los seis grandes conglomerados de la comunicación y la tendencia es a que todavía se fusionen entre sí y se vean reducidos con el tiempo. Desde luego hay unas características comunes que definen a estos conglomerados y que son la tendencia que se va a imponer en un futuro:

- Todos ellos están conectados a redes financieras y tecnológicas, a la industria de las telecomunicaciones.

- Se han ido fusionando progresivamente y esta dinámica proseguirá en el futuro.

- Establecen entre ellos alianzas o acuerdos coyunturales para acciones concretas y para la compra-venta de productos mensajísticos. 
- Es frecuente que compartan la propiedad de alguna empresa mediática o de otro tipo, a través del accionariado. Por ej., Time Warner y Vivendi son ambas propietarias de la cadena europea de información $\mathrm{CNN}+$.

- Fijan el "orden del día" del mundo a través de sus servicios audiovisuales y de prensa (News Corporation tiene una fuerte influencia en la agencia Reuter).

- Influyen en mayor o menor medida en la cultura, en la mentalidad de la gente y en la configuración de la opinión pública. Desde finales de la segunda guerra mundial vienen construyendo nuestro universo simbólico.

- Son globalmente locales y localmente globales (el canal de música MTV de ViacomCBS, trata de adaptar sus contenidos, en parte, a la zona cultural donde se observe). Sin embargo, la transmisión del mensaje es cualitativa y sustancialmente similar.

- No tienen un contrapoder o contracultura similar a la de ellos, es imposible por su poder mediático, pese a la facilidad que le otorga a los medios contraculturales internet.

- El receptor está obligado a contrarrestar sus posibles influencias negativas recurriendo a otras fuentes de formación y de información, que en muchas ocasiones no se encuentran al alcance de todos. (Reig,2004: 77)

Cómo podemos comprobar la globalización también ha empujado a los medios de comunicación hacia la concentración. Las compañías familiares han desaparecido y se han visto envueltas en grandes empresas devoradas por la vorágine bursátil y las leyes del mercado, que desde luego han impuesto sus normas y han pasado su factura. Sin protección pero tampoco sin restricciones reguladoras, los grupos de comunicación se han consolidado fusionándose entre sí para evitar ser devorados por otro gigante de mayor talla. Su tamaño por lo tanto, ha tenido que ir creciendo y esa es la tendencia futura, el seguir creciendo.

La globalización arrastra a los medios a su fusión y también a la diversificación de sus inversiones, como así nos describe la situación Ana Isabel Segovia:

Recapitulando las tendencias actuales, se podría decir que el objetivo de las corporaciones multimedia es participar en todos los sectores posibles, y aprovechar la cuota de mercado existente a través de promociones cruzadas para consolidarse como empresas y como marca. Quizás el ejemplo más conocido en este sentido sea el de Disney: cuando sus estudios lanzan una película nueva, está se promociona en sus parques de atracciones, en sus canales de televisión, en la $\mathrm{ABC}$; su compañía discográfica lanza el disco, una de sus editoriales publica el libro, sus tiendas venden los productos relacionados con la película y Mc Donalds regala juguetes promocionales con cada Happy Meal. (Reig, 2004: 82-83)

\section{La contrainformación: una alternativa al gran poder mediático. Internet una vía de escape y libertad}

La contrainformación nace como alternativa a esa gran poder mediático de los monopolios de la información, propiciada por una sociedad civil global que se manifiesta ante la globalización neoliberal impuesta y quiere dejarse oír en foros internacionales, como el de Porto Alegre, Génova o Caracas, y que utiliza las redes como medio de propagar sus ideas y su descontento. 
A qué nos referimos cuándo hablamos de contrainformación o práctica contrainformativa, nos referimos a "la voluntad de marcar una distancia radical respecto de los medios de comunicación social, por lo que contra puede no solo tener carga negativa, sino también significar "diferente", un matiz más <<propositivo>>". (López y Gimeno Perelló, 2005: 108) Y estas prácticas contrainformativas hace tiempo que podemos verlas no solo como estrategias de comunicación de algunos movimientos políticos, sino también sociales, culturales, ecológicos, etc., que generan su propia información y que no ven satisfechas sus necesidades de comunicación (su visibilidad social) en los medios convencionales.

Los medios de contrainformación son tan antiguos como la invención de la imprenta, desde ese mismo momento a la vez que se imprimían los periódicos de la época, ya también se imprimían fancines contrainformativos, el momento histórico de mayor auge de la contrainformación de la prensa coincidió con la Revolución Francesa. En este siglo XXI el medio de contrainformación rey es Internet, la red hace posible que con un coste muy pequeño y una gran facilidad de difusión y distribución que no tienen los medios escritos se llegué a una amplia población, unida por los mismos intereses e ideas y distanciada en la geografía del orbe.

Medios de contrainformación podíamos citar muchos (aunque aquí vamos a citar solo tres que se gestaron en España y dos de ámbito internacional) que poseen una dirección de Internet y algunos de ellos han alcanzado un gran prestigio, a los que cada día se suman nuevas direcciones de páginas web como estas:

- Nodo50 (www.nodo50.org): Es un servicio de contrainformación y proveedor de servicios de internet para movimientos sociales. Comienza su andadura en 1994 como centro difusor del foro "Las otras voces del planeta", celebrado en Madrid en 1994, en contra del cincuenta aniversario de dos de los organismos internacionales (Fondo Monetario Internacional y Banco Mundial), y tiene como fin conectar a los movimientos europeos y americanos contrarios a la globalización. Hoy se ha convertido en un medio de noticias, aunque sigue conectando a grupos y organizaciones de amplio espectro de la izquierda política y social del estado español y latinoamericano.

- Rebelión (www.rebelion.org): Es un periódico alternativo que surgió en Madrid en 1996, y se ha convertido en un sólido espacio virtual de noticias mundiales alternativas. Es un espacio alternativo de información con mayor proyección y difusión.

- Periódico diagonal (www.diagonalperiodico.net): Diagonal al igual que Rebelión no es una red de contrainformación, sino un periódico, un periódico digital cuya estructura es igual a la de un periódico tradicional, que además también se edita en papel. Su periodicidad es quincenal y se diferencia de los demás periódicos en que su nacimiento y sus noticias se encuentran ligadas a los movimientos sociales, que conforman esta sociedad civil global que se deja oír a través de medios de información como este.

- Indymedia (www.indymedia.org): Es una red que nace en medio de la contracumbre de Seattle a finales de 1999 con el fin de servir de herramienta de comunicación de todos los movimientos de resistencia a la globalización. Sus siglas significan independent media center y es un servicio contrainformativo de gran difusión, que ade- 
más de publicar sus informaciones en inglés, también se publican en otros idiomas: alemán, griego, español, francés, italiano, portugués y neerlandés.

- Democracy Now (www.democracynow.org): Otro de los medios más importantes e influyentes de contrainformación a nivel mundial que, además del periódico digital, posee su propio canal de radio y de televisión. Su directora es la periodista norteamericana Amy Goodman, una mujer muy influyente gracias a este medio, además de ser una mujer valiente que a través de las ondas ha sido muy crítica con el gobierno de Bush y con la guerra de Irak, hasta el punto de hacer afirmaciones como éstas en las que vemos el gran poder de los grandes grupos de comunicación: "Si nos fijamos en la guerra del golfo Pérsico, General Electric poseía la $\mathrm{ABC}$, y aún es suya. La CBS era propiedad de Westinghouse. Westinghouse y General Electric, dos de los mayores fabricantes del mundo de armas nucleares, produjeron la mayoría de las piezas para la mayoría de las armas empleadas en la guerra del golfo Pérsico. Tenemos que arrebatar los medios informativos a estas empresas multinacionales que se benefician de la guerra y devolvérselos al pueblo. Porque estos magnates de los medios de comunicación están utilizando nuestras ondas, que son de propiedad pública, que son un tesoro nacional. Necesitamos unos medios que faciliten un foro que allane los obstáculos." (Estévez y Taibo, 2008: 146) Las palabras de Amy Goodman pueden parecernos un tanto duras, pero no lo son tanto si tenemos en cuenta que los canales $\mathrm{ABC}$ y CBS son canales públicos norteamericanos y para que fines fueron utilizados en su momento. Esto nos hace reflexionar sobre el decisivo papel que tienen los grandes grupos multimedia de comunicación, y cómo estos debido a su poder se han constituido en los amos del mundo.

\section{Conclusiones}

De esta investigación podemos extraer varias conclusiones: la principal es que en este siglo XXI nos encontramos sumidos en un mundo global que ya se hace irreversible su vuelta atrás. Una globalidad que afecta a los medios de comunicación de masas, ya no existe aquel periódico familiar tal como lo conocimos en el siglo pasado, fundado y dirigido por una familia, hoy ese mismo rotativo que se constituyó en medio de referencia después de muchos años de buen hacer, pertenece hoy a un gran conglomerado multimedia, que a su vez se encuentra relacionado con el poder financiero, que además es accionista de la poderosa industria de las telecomunicaciones, que constituyen el canal que hace posible que se transmita el mensaje. Un mensaje también global que hace que prácticamente todo el orbe reciba las mismas imágenes, la misma información con la que configuramos nuestra opinión y que decide incluso a quienes votamos, según el mayor o menor poder de ese mensaje multimedia, hasta el punto de arrebatarle el poder a los políticos en aras de una democracia participativa que de alguna forma hoy se encuentra dirigida por este gran poder mediático.

Seis grandes grupos multimedia son los nuevos amos del mundo: poseen y controlan la información que llega a todos nuestros hogares. Seis grupos que seguirán fusionándose entre sí; que se encuentran íntimamente conectados a las redes financieras y a la industria de las telecomunicaciones; que fijan el orden del día de la agenda informativa mundial; que son nuestros referente y configuran la opinión pública; y sobre todo, 
que no tienen un contrapoder al mismo nivel global que el de estos grupos multimedia.

Por ello nuestra conclusión final es que nunca como en este siglo el ciudadano ha tenido a su alcance tanta información y en cambio nunca se ha sentido tan desinformado, incluso tan manipulado, hasta el punto de tener que contrastar la información que recibe todos los días, si quiere encontrarse verdaderamente informado y bien informado. Es cierto que han surgido gracias a la red Internet otras vías de escape e información para esta sociedad civil que se manifiesta y desea dejarse oír. No tienen el poder mediático de los seis grandes conglomerados de comunicación, pero sí algunos de ellos tienen un gran poder entre un grupo fiel de seguidores, que también son escuchados por la opinión pública. Lo que es cierto es que la mayoría de estos grupos de información se encuentran cercanos a partidos de izquierda y grupos sociales comprometidos con la realidad ciudadana, que puede dejar excluidos a algunos públicos cuyo pensamiento no es el mismo, pero estos también pueden dejarse oír a través de la red, que hace posible que sean hoy en día no solo receptores del mensaje, sino también emisores del mismo.

\section{Referencias bibliográficas}

BECK, Ulrich (2008): ¿Qué es la globalización? Falacias del globalismo, respuestas a la globalización. Barcelona, Paidós.

CASTELLS, Manuel (2009): Comunicación y poder. Madrid, Alianza Editorial.

CELA, Julia R. (2005): "Sociedad del conocimiento y sociedad global de la información: implantación y desarrollo en España”, en: Documentación de las Ciencias de la Información, vol, 28, pp. 147-158.

ESTÉVEZ, Carlos y TAIBO, Carlos, (eds., 2008): Voces contra la globalización. Barcelona, Crítica.

KALDOR, Mary (2005): La sociedad civil global. Una respuesta global. Barcelona, Tusquets.

LÓPEZ LÓPEZ, Pedro y GIMENO PERELLÓ, Javier (coords., 2005): Información, conocimiento y bibliotecas en el marco de la globalización neoliberal. Gijón, Ediciones Trea.

REIG, Ramón (2004): Dioses y diablos mediáticos. Cómo manipula el Poder a través de los medios de comunicación. Barcelona, Urano Tendencias.

REIG, Ramón (2011): Los dueños del periodismo. Claves de la estructura mediática mundial y de España. Barcelona, Gedisa.

SARTORI, Giovanni (2005): Homo videns. La sociedad teledirigida. Madrid, Taurus.

STIGLITZ, Joseph E. (2006): Cómo hacer que funcione la globalización. Madrid, Taurus.

VIDAL BENEYTO, José, (dir., 2002): La ventana global. Madrid, Taurus. 